\title{
Determination of REEs and Difficult Trace Elements (Be, Ge, Mo, Sn, W, Hf, Ta, and U) in 32 International Stream Sediment and Soil Reference Samples by $\mathrm{LiBO}_{2}-\mathrm{Li}_{2} \mathrm{~B}_{4} \mathrm{O}_{7}$ Fusion
Followed by ICP-MS Measurement
}

\author{
N.K. Roy*, A.K. Nandy, and J.K. Manjhi \\ Central Chemical Laboratory, Geological Survey of India, \\ 15 A\&B, Kyd Street, Kolkata - 700016, India
}

\section{INTRODUCTION}

Introduction of the National Geochemical Mapping Programme (NGCM) in the Geological Survey of India has presented a major challenge to geochemical laboratories. The demand of the programme requires analysis of a large number of samples, mainly stream sediments and soils, for the determination of 68 elements at their crustal abundance limits in a reasonable period of time. Several instrumental techniques have been utilized for the determination of these elements (1). Inductively coupled plasma mass spectrometry (ICP-MS) has been earmarked for the determination of rare earth elements (REEs) and 8 other low level difficult trace elements (Be, Ge, Sn, Mo, W, Hf, $\mathrm{Ta}$, and $\mathrm{U}$ ).

ICP-MS has been recognized as the most important instrumental tool for the determination of rare REEs and other low level elements in geological samples $(2,3,4)$. However, sample digestion is the most vital stage in the process of chemical analysis of geological samples. Open vessel digestion employing Teflon ${ }^{\circledR}$ beakers is the most common method for the digestion of geological samples. However, stream sediment and soil samples are not decomposed completely due to the presence of refractory minerals such as zirconium. There-

*Corresponding autbor.

E-mail: nk_gsi@rediffmail.com

\begin{abstract}
Lithium metaborate and lithium tetraborate fusion followed by ICP-MS measurement of 32 international stream sediment and soil reference samples for the determination of 22 elements (14 REEs and the trace elements Be, Ge, Mo, Sn, W, Hf, $\mathrm{Ta}$, and $\mathrm{U}$ ) are reported in this paper. Most of the data are in good agreement with the published certified values. Some of the data are reported for the first time by the present authors. All of these data are the mean of five separate dissolutions and analyses. Precision for most of the elements is generally better than $10 \%$ RSD for elemental concentrations $>1$ ppm and 10-20\% RSD for elemental concentrations $<1 \mathrm{ppm}$.
\end{abstract}

fore, the quantitative recovery of heavy REEs and other trace elements is low $(5,6)$. Alkali fusion in the residual acid of the undissolved part is often needed for complete decomposition of the sample (7).

Closed vessel digestion is also used for the decomposition of stream sediment and soil samples. For the dissolution of samples, Liang et al. (8) employed acid digestion in PTFE-lined stainless steel bombs at $200{ }^{\circ} \mathrm{C}$ for 12 hours. In a similar study, Revellion et al. (9) achieved dissolution of stream sediment (JSD-1, JSD-2, JSD-3) and lake sediment samples (JLK-1 and LKSD1) in high pressure Teflon vessel bombs in more than seven days. The methods described by these authors are tedious and time-consuming and cannot be used for routine analysis of stream sediment and soil samples.

Microwave digestion has also been employed by several authors for the dissolution of geological samples (10-12). Sengupta et al. (13) in their study used a mixture of $\mathrm{HF}, \mathrm{HNO}_{3}$, and $\mathrm{HCl}$ for the rapid dissolution of silicate rocks and stream sediment reference samples, followed by ICP-MS measurement of different elements including REEs. Ivanova et al. (14) reported the successful determination of REEs, Be, Bi, Ti, Th, and Y by ICPMS using microwave digestion. In a recent study, however, the present authors (15) observed that microwave digestion may be applied for the extraction of REEs and other trace elements (Ge, Be, Mo, etc.), but Sn, W, Ta, and Hf are only partially extracted. The reason may be due to the refractory nature of the minerals present in the samples.

For the complete dissolution of geological samples, alkaline fusion was most effective. Lithium metaborate was used for the decomposition of a wide range of geological samples, and good recovery of a large number of trace elements, including REEs, was obtained $(5,6)$. However, these authors did not report $\mathrm{Sn}$ and $\mathrm{W}$ in their investiga- 
tion. For the complete recovery of REEs in sedimentary reference rocks issued by the Geological Survey Japan, acid digestion followed by alkali fusion of the undissolved part was also employed (7).

Taicheng et al. (16) and Bayon et al. (17) employed $\mathrm{NaOH}-\mathrm{Na}_{2} \mathrm{O}_{2}$ as the fusion flux, followed by preconcentration of trace elements using $\mathrm{Fe}(\mathrm{OH})_{3}-\mathrm{Ti}(\mathrm{OH})_{4}$ prior to ICP-MS analysis. A literature survey, however, shows that only limited work has been carried out for the ICP-MS analysis of stream sediment and soil samples. Besides, many of the trace element data are achieved using neutron activation analysis (NAA) and some of the trace elements are not reported at all.

The purpose of the present work was to develop a simple fusion procedure for the dissolution of stream sediment and soil samples followed by ICP-MS measurement, and also to compare available data with the recommended values for 32 international stream sediment and soil reference samples.

\section{EXPERIMENTAL}

\section{Instrumentation}

A PerkinElmer ${ }^{\circledR}$ Model ELAN® ${ }^{\circledR}$ DRC $^{\text {TM }}$-e ICP-MS instrument with a cross-flow nebulizer was used throughout this work (PerkinElmer, Inc., Shelton, CT, USA). The spectrometer is optimized to provide $<3 \% \mathrm{CeO}^{+} / \mathrm{Ce}^{+}$and $\mathrm{Ba}^{++} / \mathrm{Ba}^{+}$and optimum intensity of the analytes. The instrumental parameters and measurement conditions are given in Table I.

\section{Reagents and Standard Solutions}

The reagents used in this work are as follows: $\mathrm{LiBO}_{2}$ (Spectromelt A-20), $\mathrm{Li}_{2} \mathrm{~B}_{4} \mathrm{O}_{7}$ (Spectromelt A-10), and concentrated $\mathrm{HCl}$ and $\mathrm{HNO}_{3}$ purified (by sub-boiling or of redistilled AR grade). High purity water $\left(18 \mathrm{M}^{\prime} \Omega \mathrm{cm}\right)$, prepared with a Milli- pore ${ }^{\circledR}$ Milli-Q ${ }^{\mathrm{TM}}$ system, was used throughout the procedure. Approximately $8 \%$ acid mixture $(5 \mathrm{~L}$ ) was prepared by mixing $300 \mathrm{~mL}$ concentrated $\mathrm{HNO}_{3}, 200 \mathrm{~mL}(1: 1) \mathrm{HCl}$, and $4500 \mathrm{~mL}$ high purity water. Multielement standards (10 ppm) were obtained from the manufacturer and diluted to $10 \mathrm{ppb}$ for optimization and mass calibration of the instrument.

\section{Analtytical Procedure}

In a Pt-crucible, $0.1000 \mathrm{~g}(-200$ mesh) reference sample, $0.20 \mathrm{~g}$ of lithium metaborate, and $0.15 \mathrm{~g}$ of lithium tetraborate (both Spectromelt A-20 and A-10, respectively) were added. The contents were mixed thoroughly with a Teflon rod. The Pt-crucible was placed in a high temperature muffle furnace and heated at a slow ramp rate $\left(8{ }^{\circ} \mathrm{C}\right)$ up to $550{ }^{\circ} \mathrm{C}$, then the temperature was raised to $1100^{\circ} \mathrm{C}$ at high ramp $\left(10^{\circ} \mathrm{C}\right)$. The furnace remained at $1100^{\circ} \mathrm{C}$ for 45 minutes for complete fusion of the sample. The furnace was then allowed to cool to $200{ }^{\circ} \mathrm{C}$ before the Ptcrucible was removed, cooled, and placed in a 100-mL beaker. Next, $25 \mathrm{~mL}$ of the $8 \%$ acid mixture was added to the Pt-crucible, and the beaker containing the Pt-crucible was placed in a magnetic stirrer and stirred for 30 minutes to completely dissolve the solid. The Pt-crucible was removed from the beaker and the solution transferred to a $250-\mathrm{mL}$ volumetric flask. Next, $10 \mathrm{~mL}$ of $250 \mathrm{ppb}$ indium solution was added to the flask, and made up to volume with high purity water. The final solution contained $4 \%$ acid and $0.18 \%$ salt concentration (TDS was $<0.2 \%$ ), suitable for aspiration. The solution was stored in a $100-\mathrm{mL}$ high density polythene bottle prior to ICP-MS measurement.

\section{Isotope Used and Detection Limits}

The isotopes used for the determination of these 22 elements are the most abundant of each element, with most being free from isobaric overlap. The detection limits and quantification limits for the different elements are listed in Table II.

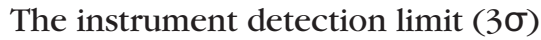
for the elements is calculated from dilute nitric acid. The limit of quantification $(10 \sigma)$ is calculated from the reagent blank after taking into consideration the dilution factor. The instrument detection limits and limits for quantification are given in Table III.

TABLE I

ICP-MS Instrumental Parameters and Measurement Conditions

RF Power
Lens Voltage
Plasma Argon Gas Flow Rate
Auxiliary Argon Gas Flow Rate
Nebulizer Argon Gas Flow Rate
Integration Time
Dwell Time
Acquisition Mode/No. of Sweeps
No. of Replicates
Wash Solution
Wash Time

$1000 \mathrm{~W}$

$8.50 \mathrm{~V}$

$15 \mathrm{~L} / \mathrm{min}$

$1.10 \mathrm{~L} / \mathrm{min}$

$0.85 \mathrm{~L} / \mathrm{min}$

$1000 \mathrm{~ms}$

$50 \mathrm{~ms}$ per amu

Peak hopping/60

3

Ultrapure Water, $1 \% \mathrm{HNO}_{3}$

30 sec 


\section{Interference Correction}

The software provided by the instrument manufacturer allows automatic correction of isobaric interferences. With the optimization of the instrument, the formation of oxides and doubly charged ions are brought to $<3 \%$, meaning that oxide interferences are insignificant. In addition, interference corrections were also applied to the different elements (Table II).

\section{Standard Reference Materials}

The 33 standard reference materials (SRMs) used in this work were Chinese Stream Sediments (GSD-1a, GSD-2 to GSD-12), Chinese Soil (GSS-1 to GSS-8), Canadian Stream
Sediment (STSD 1 to 4), Japanese Stream Sediment (JSD 1-3), South African Stream Sediment (SARM-46, SARM-51, SARM-52), South African Soil (SARM-42), and Canadian Soil (SO-2, SO-3). Of these 33 SRMs, GSD-5 was used for calibration.

\section{Selection of Calibration Standard}

Calibration with a pure synthetic standard solution was not found to be suitable for the present study of standard reference materials. Stream sediments and soil samples contain high concentrations of iron, aluminum, calcium, and magnesium (more than $15 \%$ in some cases), and matrix matching is required for calibration work.

TABLE II

Isotopes Used and Interferences

\begin{tabular}{|c|c|c|c|c|}
\hline Elements & $\begin{array}{c}\text { Mass (amu) } \\
\text { Selected }\end{array}$ & $\begin{array}{c}\text { Abundances } \\
(\%)\end{array}$ & Interferences & $\begin{array}{l}\text { Corrections } \\
\text { applied for: }\end{array}$ \\
\hline $\mathrm{Be}$ & 9.0122 & 100 & Free & \\
\hline $\mathrm{Ge}$ & 73.9219 & 35.94 & $\mathrm{Se}, \mathrm{ArS}, \mathrm{Nd}^{2+}, \mathrm{Sm}^{2+}$ & $\mathrm{Se}$ \\
\hline Mo & 97.9055 & 24.13 & $\mathrm{Ru}$ & \\
\hline Sn & 117.902 & 24.20 & $\mathrm{MoO}, \mathrm{U}^{2+}$ & $\mathrm{Ru}$ \\
\hline $\mathrm{La}$ & 138.906 & 99.9 & Free & \\
\hline $\mathrm{Ce}$ & 139.905 & 88.5 & Free & \\
\hline $\operatorname{Pr}$ & 140.907 & 100 & Free & \\
\hline $\mathrm{Nd}$ & 142.91 & 12.18 & Free & \\
\hline $\mathrm{Sm}$ & 146.915 & 15.00 & Free & \\
\hline $\mathrm{Eu}$ & 150.92 & 47.8 & $\mathrm{BaO}$ & \\
\hline Gd & 157.924 & 24.84 & Dy,NdO,PrO,CeO & Dy \\
\hline $\mathrm{Tb}$ & 158.925 & 100 & $\mathrm{Pr}, \mathrm{NdO}$ & \\
\hline Dy & 163.929 & 28.2 & $\mathrm{Er}, \mathrm{SmO}, \mathrm{NdO}$ & $\mathrm{Er}$ \\
\hline Ho & 164.93 & 100 & $\mathrm{SmO}$ & \\
\hline $\mathrm{Er}$ & 166.932 & 22.95 & $\mathrm{EuO}, \mathrm{SmO}$ & \\
\hline $\mathrm{Tm}$ & 168.934 & 100 & $\mathrm{EuO}$ & \\
\hline $\mathrm{Yb}$ & 171.937 & 21.9 & DyO, GdO, SmO & \\
\hline $\mathrm{Lu}$ & 174.941 & 97.4 & GdO, ErO, DyO & \\
\hline Hf & 177.944 & 27.2 & GdO, ErO, DyO & \\
\hline $\mathrm{Ta}$ & 180.948 & 99.9 & Free & \\
\hline W & 181.948 & 26.3 & Free & \\
\hline $\mathrm{U}$ & 238.05 & 99.3 & Free & \\
\hline
\end{tabular}

\section{Atomic Spectroscopy \\ 1 Vol. 33(5), Sept./Oct. 2012}

Even matrix matching with the addition of different salt solutions in the pure synthetic standard solution did not yield the desired results. Therefore, matrix matching with a standard reference material was used for calibration. It was found that the stream sediment reference material sample GSD-5 is the most suitable standard to cope with all types of stream sediment and soil samples. Therefore, SRM GSD-5 was used as the calibration standard in this work. Since the calibration curve in ICP-MS is linear over five to six orders of magnitude, the instrument was calibrated with only one point single standard.
TABLE III Instrumental Detection and Quantification Limits

\begin{tabular}{ccc}
\hline Element & $\begin{array}{c}\text { Detection } \\
\text { Limit }^{\mathrm{a}}(\mathrm{ng} / \mathrm{mL})\end{array}$ & $\begin{array}{c}\text { Quantification } \\
\text { Limit }^{\mathrm{b}}(\mu \mathrm{g} / \mathrm{g})\end{array}$ \\
\hline $\mathrm{Be}$ & 0.018 & 0.15 \\
$\mathrm{Ge}$ & 0.003 & 0.025 \\
$\mathrm{Mo}$ & 0.030 & 0.25 \\
$\mathrm{Sn}$ & 0.060 & 0.50 \\
$\mathrm{La}$ & 0.060 & 0.50 \\
$\mathrm{Ce}$ & 0.120 & 1.0 \\
$\mathrm{Pr}$ & 0.005 & 0.037 \\
$\mathrm{Nd}$ & 0.003 & 0.025 \\
$\mathrm{Sm}$ & 0.003 & 0.025 \\
$\mathrm{Eu}$ & 0.0004 & 0.002 \\
$\mathrm{Gd}$ & 0.0015 & 0.012 \\
$\mathrm{~Tb}$ & 0.0016 & 0.015 \\
$\mathrm{Dy}$ & 0.0006 & 0.005 \\
$\mathrm{Ho}$ & 0.0006 & 0.005 \\
$\mathrm{Er}$ & 0.0009 & 0.007 \\
$\mathrm{Tm}$ & 0.0007 & 0.007 \\
$\mathrm{Yb}$ & 0.0002 & 0.01 \\
$\mathrm{Lu}$ & 0.0001 & 0.007 \\
$\mathrm{Hf}$ & 0.030 & 0.25 \\
$\mathrm{Ta}$ & 0.012 & 0.10 \\
$\mathrm{~W}$ & 0.030 & 0.25 \\
$\mathrm{U}$ & 0.030 & 0.25 \\
\hline
\end{tabular}

$\mathrm{a}=3 \sigma$ (in solution).

$\mathrm{b}=10 \sigma$ (in rock). $2500 \times$ (dilution factor). 


\section{Blank Correction}

Blanks were measured along with the samples, but the instrument software automatically subtracts the blank from the sample measurement. Since all of the reagents and water used were of very high purity, contamination from these reagents was insignificant.

\section{RESULTS AND DISCUSSION}

Geological samples, particularly stream sediments and soils, are complicated in nature, and complete dissolution of these samples is very tedious and time-consuming. Alkali fusion is the most effective method for dissolution of such materials. Most of the works on fusion used $\mathrm{LiBO}_{2}$ as the fusion agent. However, the authors observed that fusion with $\mathrm{LiBO}_{2}$ produced a glassy solid mass which is difficult to dissolve. Instead, if a mixture of $\mathrm{LiBO}_{2}$ and $\mathrm{Li}_{2} \mathrm{~B}_{4} \mathrm{O}_{7}$ is used, the fusion mass was easily dissolved in an acid mixture. Moreover, it was observed that fusion can be achieved at a lower temperature when the fusion mixture of $\mathrm{LiBO}_{2}$ and $\mathrm{Li}_{2} \mathrm{~B}_{4} \mathrm{O}_{7}$ was used. Complete dissolution of all samples was achieved with this fusion mixture. It was further observed that some of the trace elements, particularly Sn, W, Mo, Ta, and Hf, are unstable in dilute $\mathrm{HNO}_{3}$ solution, particularly at low concentrations. However, with the addition of $2 \% \mathrm{HCl}$, all of the trace elements were totally dissolved and quantitative recovery was obtained. Although alkali fusion increased the total salt concentration $(0.18 \%)$, it is still below the permissible limit of $0.2 \%$ in ICP-MS measurement. Any salt deposition on the sample cone was cleared by washing with $1 \% \mathrm{HNO}_{3}$ and ultra pure water for 30 seconds between sample measurements.

\section{Accuracy and Precision}

The analytical data of 32 reference stream sediment and soil samples are listed in Table IV. These data are the mean of five separate dissolutions and analyses. Along with the mean values, the standard deviation is also given for each of the elements. Precision for most of the elements is generally better than $10 \%$ RSD for elemental concentrations of $>2 \mathrm{ppm}$ and is 10-20\% RSD for elemental concentrations of 1-2 ppm. In a few cases, for very low values it is $>20 \%$ RSD. The high RSD may be due to incomplete dissolution of the samples.

The results obtained in this study for most of the elements are in good agreement with the certified values (Certified Values of Stream Sediment and Soil Reference Materials 1998 Revision by Quality and Technical Supervision, Peoples' Republic of China) (18) and the compiled values (19). However, for the STSD series, some of the values are not available. In those cases, the values were taken from Sengupta et al. (13). For SARM standards, no compiled values are available. However, NAA data are available for some of the elements and a comparison of our data was made with those data.

For the 24 elements determined in this work, bias in the measured elemental concentration values for most of the reference elements was less than $10 \%$ in comparison to the certified values.

\section{REE Values}

The REE data for Chinese sediment (GSD-1a to GSD-12) and soil samples (GSS-1 to GSS-8) are in good agreement with the certified values (Certified Values of Stream Sediment and Soil Reference Materials, 1998 Revision by Quality and Technical Supervision, Peoples' Republic of China). Most of the val- ues are within 10\% RSD. For Ho, in some of the samples the RSD is above $20 \%$. For Japanese Stream sediment samples (JSD-1 to JSD-3) our values are in good agreement with those of Yamamoto (7). These authors confirmed that the compiled values for REEs, particularly HREEs (Heavy Rare Earth Elements) are in the lower order and do not represent the true values. Most of the values are within 10\% RSD. However, for Eu (values less than $1 \mathrm{ppm}$ ) the RSD is above $20 \%$. In these three standard samples, a positive bias was observed in our values compared to the certified values for $\mathrm{La}, \mathrm{Ce}$, and Pr. However, no such bias was observed for the other elements. For the STSD series, the compiled values are not available for Pr, Gd, Ho, Er, and Tm. The data for these elements were taken from Sengupta et al. (13) for comparison. Our data for all of the REEs are in excellent agreement with the compiled data and also with Sengupta's data. Most of the values are within 10\% RSD. For Lu (values $<1 \mathrm{ppm}$ ), the RSD is slightly above $20 \%$. For SARM samples, no compiled data are available. For comparison with our data, the NAA results from Korotev (20) were used. Besides providing the eight REEs which are generally available using the NAA technique, some values for other REEs (Pr, Gd, Dy, Ho, $\mathrm{Er}$, and $\mathrm{Tm}$ ) are also given by the author. Comparing our data with the data of the NAA technique, we observed that all our REE data, except La for SARM-42 and SARM51, Ce for SARM-42, SARM-46 and SARM-52, Nd for SARM 42 and SARM 46, Pr and Sm for SARM-42, are in good agreement. For the So-2 and So-3 samples, all REE values are in good agreement with our compiled data. However, Mo for So-3 and Ta for the So-2 and So-3 samples show some disagreement with the compiled values. The RSD for most of the elements is within $10 \%$. 


\section{Atomic Spectroscopy \\ 1 Vol. 33(5), Sept./Oct. 2012}

\section{Eight Other Trace Elements}

Besides the REEs, eight other trace elements (Be, Ge, Mo, Sn, W, $\mathrm{Ta}$, Hf, and U) were also determined. All of these elements (except Sn in a few samples) show good agreement with the certified values (Certified Values of Stream Sediment and Soil Reference Materials 1998 Revision by Quality and Technical Supervision, Peoples' Republic of China) and the compiled values. The RSDs for most of the elements are within $20 \%$. However, in only a few cases it is above $20 \%$. Most of the trace element concentrations in these sample are in the 1-2 ppm range. For Sn, our values for GSD-2, GSD-8, GSD-11, GSS-2, GSS-3, GSS-4, GSS-5, GSS-6, GSS-7, and GSS- 8 are in a higher range. Due to non-availability of literature data for $\mathrm{Sn}$ in these samples, we could not compare our data with other workers. However, our data may be more accurate than the compiled data since Chinese stream sediments and soil samples contain refractory materials which are difficult to dissolve.

\section{New Data}

For the JSD series, no literature data is available for Be, Ge, Mo, Sn, $\mathrm{Ta}$, and $\mathrm{W}$. We have reported the data for these elements by our method (see Table IV). For the SARM series, no ICP-MS data is available for the elements. It should be noted that we report the data for all of the elements by ICP-MS in this paper for the first time.

\section{CONCLUSION}

Stream sediments and soil samples are difficult to bring into solution due to the presence of refractory minerals. In this work, a mixture of $\mathrm{LiBO}_{2}$ and $\mathrm{Li} 2 \mathrm{~B}_{4} \mathrm{O}_{7}$ was employed for fusion of stream sediment and soil samples, followed by ICP-MS determination of REEs and eight difficult trace elements (Be, Ge, Mo, So, W. Hf, Ta, and U).
These elements are of great importance in petrogenic studies and no other measurement technique, except NAA, is suitable for the determination of these elements. For Chinese stream sediments and soil samples, our values are in good agreement with all of the 22 elements, except for $\mathrm{Sn}$ in some samples. In case of the JSD and STSD series of samples, our values are in good agreement with the literature values. For the SARM samples, we report for the first time the ICP-MS values for the REEs and eight other elements.

Thus, the proposed method is suitable for the determination of REEs and eight other trace elements in stream sediment and soil samples. The method is successfully being utilized in the Geological Survey of India for the analysis of a large number of stream sediment and soil samples.

\section{ACKNOWLEDGMENT}

The authors wish to thank Dr. D.K. Das, Dy. Director General (Geochemistry) and E.R. Hod (Retired) for their kind interest in this work. The authors also thank the Director General, GSI, Kolkata, for his kind permission to publish this paper.

Received July 2, 2012. 
TABLE IV

Data of ICP-MS Analysis for Chinese Stream Sediment Samples ( $\mu \mathrm{g} / \mathrm{g})$

\begin{tabular}{|c|c|c|c|c|c|c|c|c|c|c|c|}
\hline \multicolumn{2}{|c|}{ Element/Mass } & $\begin{array}{r}\text { GSD-1a } \\
\text { Certified }^{\mathrm{a}}\end{array}$ & $\begin{array}{c}\text { GSD-1a } \\
\text { Obtained }\end{array}$ & $\begin{array}{c}\text { GSD-2 } \\
\text { Certified }^{\mathrm{a}}\end{array}$ & $\begin{array}{c}\text { GSD-2 } \\
\text { Obtained }\end{array}$ & $\begin{array}{c}\text { GSD-3 } \\
\text { Certified }^{\mathrm{a}}\end{array}$ & $\begin{array}{c}\text { GSD-3 } \\
\text { Obtained }\end{array}$ & $\begin{array}{c}\text { GSD-4 } \\
\text { Certified }^{\mathrm{a}}\end{array}$ & $\begin{array}{c}\text { GSD-4 } \\
\text { Obtained }\end{array}$ & $\begin{array}{c}\text { GSD-6 } \\
\text { Certified }^{\text {a* }}\end{array}$ & $\begin{array}{c}\text { GSD-6 } \\
\text { Obtained }\end{array}$ \\
\hline $\mathrm{Be}$ & 9 & 2.90 & $3.1 \pm 0.05$ & $17.1 \pm 1.6$ & $18.75 \pm 1.5$ & $1.5 \pm 0.3$ & $1.35 \pm 0.31$ & $2.4 \pm 0.4$ & $=0.2$ & $1.7 \pm 0.4$ & $2.09 \pm 0.5$ \\
\hline $\mathrm{Ge}$ & 74 & & $1.4 \pm 0.3$ & & $2.14 \pm 0.4$ & $1.3 \pm 0.4$ & & & & & \\
\hline Mo & 98 & & & & & & & & & & \\
\hline Sn & 118 & & $3.02=$ & & $32.13 \pm 3.0$ & $3.4 \pm 0.9$ & & & & & $=1.5$ \\
\hline $\mathrm{La}$ & 39 & & 43.2 & & & & & & & & \pm 7 \\
\hline $\mathrm{Ce}$ & 140 & & 85.3 & & 188. & & 69.7 & & & & \pm 6 \\
\hline $\operatorname{Pr}$ & 141 & & $9.75 \pm 1.0$ & $18.6 \pm 2.4$ & 17.7 & $8.3 \pm 0.8$ & 8.05 & $9.3 \pm$ & 9.36 & 8.4 & 1.0 \\
\hline $\mathrm{Nd}$ & 3 & .00 & $38.25 \pm 4.0$ & & & & & & & & \\
\hline $\mathrm{Sm}$ & & & 7.02 & $10.8 \pm 1$ & 11.9 & & 5.4 & 6.2 & 6 & & 0.8 \\
\hline $\mathrm{Eu}$ & & & 1.67 & $0.49 \pm$ & & & & & & & .14 \\
\hline Gd & 58 & & 5.9 & & 10. & & & & & & \\
\hline $\mathrm{Tb}$ & 159 & & $0.92=$ & & 1.8 & $0.7=$ & 0.75 & 0.90 & 0.90 & 0.6 & 0.21 \\
\hline Dy & 164 & & $4.69=$ & & 12.25 & & 4.34 & & & & 1.2 \\
\hline Ho & & & $0.84=$ & & 2.61 & .2 & 0.84 & & 0.9 & 0.7 & 0.14 \\
\hline $\mathrm{Er}$ & 167 & & $2.45 \pm 0.41$ & $.2 \pm 0.4$ & \pm 0.5 & 0.3 & 2.52 & & 2.92 & & 0.45 \\
\hline $\mathrm{Tm}$ & & & $0.4 \pm 0.04$ & $1.55 \pm 0.17$ & $1.69 \pm 0.11$ & $0.39 \pm 0.07$ & $0.41 \pm$ & & 0.47 & & 0.08 \\
\hline $\mathrm{Yb}$ & 172 & & $2.68 \pm 0.3$ & & $11.73 \pm 2.1$ & & & & & & 0.44 \\
\hline $\mathrm{Lu}$ & 175 & & $0.4 \pm 0.06$ & $1.6 \pm 0.3$ & $1.90 \pm 0.2$ & $0.39 \pm 0.04$ & $0.43 \pm 0.05$ & $0.47 \pm 0.13$ & $0.48 \pm 0.08$ & $0.34 \pm 0.08$ & $0.37 \pm 0.07$ \\
\hline $\mathrm{Hf}$ & 178 & & $10.28 \pm 1.8$ & & $21.77 \pm 2.1$ & & & & & & $5.03 \pm 0.09$ \\
\hline $\mathrm{Ta}$ & 181 & 3.00 & $3.34 \pm 0.34$ & $15.3 \pm 1.0$ & $16.15 \pm 1.1$ & $1.0 \pm 0.2$ & $1.12 \pm 0.18$ & $1.4 \pm 0.1$ & $1.42 \pm 0.08$ & $0.75 \pm 0.08$ & $0.80 \pm 0.08$ \\
\hline W & 182 & & $0.97 \pm 0.4$ & & $25.93 \pm 2.8$ & & & & $2.30 \pm 0.9$ & & $28.19 \pm 3$ \\
\hline $\mathrm{U}$ & 238 & 4.60 & $4.54 \pm 0.8$ & $17 \pm 3$ & $17.50 \pm 2.9$ & $1.9 \pm 0.5$ & $1.67 \pm 0.3$ & $2.6 \pm 0.6$ & $2.52 \pm 0.4$ & $2.4 \pm 0.5$ & $2.50 \pm 0.2$ \\
\hline
\end{tabular}

TABLE- IV (continued)

Data of ICP-MS Analysis for Chinese Stream Sediment Samples $(\mu \mathrm{g} / \mathrm{g})$

\begin{tabular}{|c|c|c|c|c|c|c|c|c|c|}
\hline \multirow{2}{*}{\multicolumn{2}{|c|}{ Element/Mass }} & \multicolumn{2}{|c|}{ GSD-7 } & \multicolumn{2}{|c|}{ GSD-8 } & \multicolumn{2}{|c|}{ GSD-9 } & \multicolumn{2}{|c|}{ GSD-10 } \\
\hline & & Certified $^{\mathrm{a}}$ & Obtained & Certified $^{\mathrm{a}}$ & Obtained & Certified $^{\mathrm{a}}$ & Obtained & Certified $^{\mathrm{a}}$ & Obtained \\
\hline $\mathrm{Be}$ & 9 & $2.7 \pm 0.4$ & $3.25 \pm 0.5$ & $2.0 \pm 0.3$ & $1.98 \pm 0.2$ & $1.8 \pm 0.4$ & $1.86 \pm 0.35$ & $0.9 \pm 0.3$ & $0.97 \pm 0.2$ \\
\hline $\mathrm{Ge}$ & 74 & $1.4 \pm 0.4$ & $1.49 \pm 0.3$ & $0.94 \pm 0.27$ & $0.97 \pm 0.33$ & $1.3 \pm 0.2$ & $1.28 \pm 0.22$ & $0.40 \pm 0.06$ & $0.49 \pm 0.05$ \\
\hline Mo & 98 & $1.4 \pm 0.2$ & $1.58 \pm 0.3$ & $0.54 \pm 0.19$ & $0.57 \pm 0.18$ & $0.64 \pm 0.16$ & $0.83 \pm 0.25$ & $1.2 \pm 0.2$ & $1.11 \pm 0.2$ \\
\hline Sn & 118 & $5.4 \pm 1.3$ & $6.31 \pm 1.5$ & $9.4 \pm 1.5$ & $10.12 \pm 1.8$ & $2.6 \pm 0.5$ & $3.65 \pm 0.45$ & $1.4 \pm 0.4$ & $1.65 \pm 0.51$ \\
\hline $\mathrm{La}$ & 139 & $45 \pm 6$ & $49.47 \pm 7.1$ & $30 \pm 5$ & $28.98 \pm 5.2$ & $40 \pm 4$ & $42.11 \pm 4.5$ & $13 \pm 14$ & $3.20 \pm 1.2$ \\
\hline $\mathrm{Ce}$ & 140 & $78 \pm 7$ & $82.55 \pm 7.8$ & $54 \pm 6$ & $53.50 \pm 5.4$ & $78 \pm 9$ & $86.55 \pm 10$ & $38 \pm 5$ & $37.29 \pm 4.8$ \\
\hline $\operatorname{Pr}$ & 141 & $9.6 \pm 1.1$ & $10.48 \pm 1.20$ & $5.8 \pm 0.5$ & $5.89 \pm 0.8$ & $9.2 \pm 0.9$ & $9.74 \pm 0.88$ & $3.2 \pm 0.4$ & $3.66 \pm 0.32$ \\
\hline $\mathrm{Nd}$ & 143 & $37 \pm 6$ & $35.84 \pm 5.2$ & $21 \pm 2$ & $20.70 \pm 3.1$ & $34 \pm 3$ & $36.43 \pm 0.3$ & $11.8 \pm 1.6$ & $12.45 \pm 1.5$ \\
\hline Sm & 147 & $6.1 \pm 0.5$ & $6.29 \pm 0.6$ & $3.8 \pm 0.3$ & $3.95 \pm 0.4$ & $6.3 \pm 0.5$ & $6.72 \pm 0.58$ & $2.4 \pm 0.2$ & $2.50 \pm 0.3$ \\
\hline Eu & 151 & $1.3 \pm 0.2$ & $1.43 \pm 0.3$ & $0.56 \pm 0.08$ & $0.62 \pm 0.12$ & $1.33 \pm 0.09$ & $1.51 \pm 0.12$ & $0.47 \pm 0.05$ & $0.50 \pm 0.05$ \\
\hline Gd & 158 & $5.8 \pm 0.8$ & $6.50 \pm 0.9$ & $3.5 \pm 0.6$ & $3.89 \pm 0.7$ & $5.5 \pm 0.4$ & $5.81 \pm 0.5$ & $2.2 \pm 0.3$ & $2.42 \pm 0.22$ \\
\hline $\mathrm{Tb}$ & 159 & $0.76 \pm 0.14$ & $0.89 \pm 0.15$ & $0.54 \pm 0.09$ & $0.54 \pm 0.10$ & $0.87 \pm 0.13$ & $0.99 \pm 0.15$ & $0.42 \pm 0.11$ & $0.43 \pm 0.18$ \\
\hline Dy & 164 & $4.2 \pm 0.7$ & $4.52 \pm 0.66$ & $2.6 \pm 0.4$ & $2.65 \pm 0.26$ & $5.1 \pm 0.3$ & $5.25 \pm 0.4$ & $2.2 \pm 0.3$ & $2.61 \pm 0.29$ \\
\hline Ho & 165 & $0.96 \pm 0.21$ & $0.91 \pm 0.30$ & $0.9 \pm 0.2$ & $0.85 \pm 0.2$ & $0.96 \pm 0.08$ & $1.05 \pm 0.09$ & $0.45 \pm 0.08$ & $0.51 \pm 0.05$ \\
\hline $\mathrm{Er}$ & 167 & $2.3 \pm 0.2$ & $2.35 \pm 0.2$ & $1.8 \pm 0.3$ & $2.07 \pm 0.25$ & $2.8 \pm 0.3$ & $3.13 \pm 0.31$ & $1.3 \pm 0.2$ & $1.49 \pm 0.18$ \\
\hline $\mathrm{Tm}$ & 169 & $0.44 \pm 0.09$ & $0.44 \pm 0.08$ & $0.33 \pm 0.06$ & $0.35 \pm 0.05$ & $0.44 \pm 0.09$ & $0.50 \pm 0.06$ & $0.2 \pm 0.04$ & $0.24 \pm 0.03$ \\
\hline $\mathrm{Yb}$ & 172 & $2.6 \pm 0.4$ & $2.82 \pm 0.5$ & $2.1 \pm 0.4$ & $2.39 \pm 0.3$ & $2.8 \pm 0.4$ & $3.26 \pm 0.6$ & $1.2 \pm 0.3$ & $1.45 \pm 0.2$ \\
\hline $\mathrm{Lu}$ & 175 & $0.39 \pm 0.07$ & $0.45 \pm 0.1$ & $0.38 \pm 0.07$ & $0.40 \pm 0.05$ & $0.45 \pm 0.04$ & $0.47 \pm 0.5$ & $0.19 \pm 0.04$ & $0.23 \pm 0.03$ \\
\hline Hf & 178 & $4.9 \pm 1.0$ & $5.27 \pm 0.09$ & $14.5 \pm 1.8$ & $15.95 \pm 1.6$ & $9.7 \pm 1.6$ & $10.32 \pm 1.9$ & $1.8 \pm 0.4$ & $2.01 \pm 02$ \\
\hline $\mathrm{Ta}$ & 181 & $1.35 \pm 0.13$ & $1.48 \pm 0.15$ & $3.7 \pm 0.5$ & $4.03 \pm 0.4$ & $1.3 \pm 0.2$ & $1.36 \pm 0.18$ & 0.50 & $0.48 \pm 0.04$ \\
\hline W & 182 & $5.5 \pm 1.0$ & $6.29 \pm 1.4$ & $2.0 \pm 0.5$ & $1.73 \pm 0.4$ & $1.8 \pm 0.3$ & $1.68 \pm 0.2$ & $1.6 \pm 0.4$ & $1.46 \pm 0.3$ \\
\hline $\mathrm{U}$ & 238 & $3.5 \pm 0.5$ & $3.45 \pm 0.4$ & $3.0 \pm 0.3$ & $3.16 \pm 0.3$ & $2.6 \pm 0.6$ & $2.57 \pm 0.54$ & $2.1 \pm 0.3$ & $2.31 \pm 0.4$ \\
\hline
\end{tabular}

${ }^{a}$ Certificate of Certified values of Stream Sediment and Soil Reference Materials, 1998 Revision by Quality and Technical Supervision, P.R. China. 


\section{Atomic Spectroscopy \\ $\bigcup$ Vol. 33(5), Sept./Oct. 2012}

TABLE- IV (continued)

Data of ICP-MS Analysis for Chinese Stream Sediment Samples ( $\mu \mathrm{g} / \mathrm{g})$

\begin{tabular}{|c|c|c|c|c|c|}
\hline \multirow{2}{*}{\multicolumn{2}{|c|}{ Element/Mass }} & \multicolumn{2}{|c|}{ GSD-11 } & \multicolumn{2}{|c|}{ GSD-12 } \\
\hline & & \multirow{2}{*}{$\frac{\text { Certified }^{\mathrm{a}}}{26 \pm 4}$} & \multirow{2}{*}{$\begin{array}{l}\text { Obtained } \\
30.41 \pm 3.2\end{array}$} & \multirow{2}{*}{$\begin{array}{c}\text { Certified }^{\mathrm{a}} \\
8.2 \pm 1.1\end{array}$} & \multirow{2}{*}{$\begin{array}{c}\text { Obtained } \\
9.25 \pm 1.5\end{array}$} \\
\hline $\mathrm{Be}$ & 9 & & & & \\
\hline $\mathrm{Ge}$ & 74 & $1.81 \pm 0.23$ & $1.82 \pm 0.25$ & $1.87 \pm 0.13$ & $1.83 \pm 0.15$ \\
\hline Mo & 98 & $5.9 \pm 0.8$ & $6.59 \pm 1.0$ & $8.4 \pm 0.9$ & $8.79 \pm 1.2$ \\
\hline Sn & 118 & $370 \pm 68$ & $410.25 \pm 48$ & $54 \pm 7$ & $57.55 \pm 10$ \\
\hline $\mathrm{La}$ & 139 & $30 \pm 3$ & $32.84 \pm 4.1$ & $32.7 \pm 2.2$ & $33.75 \pm 2.5$ \\
\hline $\mathrm{Ce}$ & 140 & $58 \pm 5$ & $58.66 \pm 7.5$ & $61 \pm 5$ & $65.95 \pm 4.5$ \\
\hline $\operatorname{Pr}$ & 141 & $7.4 \pm 0.6$ & $7.08 \pm 0.7$ & $6.9 \pm 1.2$ & $7.62 \pm 1.5$ \\
\hline $\mathrm{Nd}$ & 143 & $27 \pm 3$ & $23.78 \pm 3.5$ & $26 \pm 4$ & $25.81 \pm 3.4$ \\
\hline $\mathrm{Sm}$ & 147 & $6.2 \pm 0.4$ & $5.96 \pm 0.51$ & $5.0 \pm 0.5$ & $5.40 \pm 0.4$ \\
\hline Eu & 151 & $0.6 \pm 0.08$ & $0.55 \pm 0.06$ & $0.61 \pm 0.04$ & $0.62 \pm 0.05$ \\
\hline Gd & 158 & $5.9 \pm 0.5$ & $6.23 \pm 0.7$ & $4.4 \pm 0.4$ & $4.75 \pm 0.5$ \\
\hline $\mathrm{Tb}$ & 159 & $1.13 \pm 0.14$ & $1.17 \pm 0.21$ & $0.82 \pm 0.08$ & $0.86 \pm 0.8$ \\
\hline Dy & 164 & $7.2 \pm 0.8$ & $7.45 \pm 0.78$ & $4.8 \pm 0.8$ & $5.19 \pm 1.0$ \\
\hline Ho & 165 & $1.4 \pm 0.2$ & $1.49 \pm 0.19$ & $0.94 \pm 0.09$ & $1.05 \pm 0.07$ \\
\hline $\mathrm{Er}$ & 167 & $4.6 \pm 0.6$ & $4.74 \pm 0.51$ & $3.1 \pm 0.3$ & $3.34 \pm 0.25$ \\
\hline $\mathrm{Tm}$ & 169 & $0.74 \pm 0.11$ & $0.82 \pm 0.14$ & $0.53 \pm 0.07$ & $0.60 \pm 0.06$ \\
\hline $\mathrm{Yb}$ & 172 & $5.1 \pm 0.8$ & $5.57 \pm 0.6$ & $3.7 \pm 0.5$ & $4.07 \pm 0.04$ \\
\hline $\mathrm{Lu}$ & 175 & $0.78 \pm 0.08$ & $0.89 \pm 0.10$ & $0.58 \pm 0.08$ & $0.64 \pm .09$ \\
\hline Hf & 178 & $5.4 \pm 0.5$ & $6.10 \pm 0.6$ & $8.3 \pm 1.1$ & $9.29 \pm 1.0$ \\
\hline $\mathrm{Ta}$ & 181 & $5.7 \pm 0.5$ & $5.89 \pm 0.6$ & $3.2 \pm 0.3$ & $3.54 \pm 0.03$ \\
\hline W & 182 & $126 \pm 13$ & $130.51 \pm 10$ & $37 \pm 3$ & $41.12 \pm 4.2$ \\
\hline $\mathrm{U}$ & 238 & $9.1 \pm 1.3$ & $7.90 \pm 1.1$ & $7.8 \pm 1.0$ & $7.62 \pm 0.5$ \\
\hline
\end{tabular}

TABLE- IV (continued)

Data of ICP-MS Analysis for Chinese Soil Reference Samples $(\mu \mathrm{g} / \mathrm{g})$

\begin{tabular}{|c|c|c|c|c|c|c|c|c|c|}
\hline \multirow{2}{*}{\multicolumn{2}{|c|}{ Element/Mass }} & \multicolumn{2}{|c|}{ GSS-1 } & \multicolumn{2}{|c|}{ GSS-2 } & \multicolumn{2}{|c|}{ GSS-3 } & \multicolumn{2}{|c|}{ GSS-4 } \\
\hline & & Certified $^{\mathrm{a}}$ & Obtained & Certified $^{\mathrm{a}}$ & Obtained & Certified $^{\mathrm{a}}$ & Obtained & Certified $^{\mathrm{a}}$ & Obtained \\
\hline $\mathrm{Be}$ & 9 & $2.5 \pm 0.4$ & $2.70 \pm 0.45$ & $1.8 \pm 0.3$ & $1.80 \pm 0.02$ & $1.4 \pm 0.3$ & $1.43 \pm 0.26$ & $1.85 \pm 0.53$ & $1.75 \pm 0.32$ \\
\hline $\mathrm{Ge}$ & 74 & $1.34 \pm 0.21$ & $1.37 \pm 0.23$ & $1.2 \pm 0.2$ & $1.15 \pm 0.18$ & $1.17 \pm 0.22$ & $1.03 \pm 0.2$ & $1.9 \pm 0.4$ & $1.94 \pm 0.4$ \\
\hline Mo & 98 & $1.4 \pm 0.2$ & $1.57 \pm 0.20$ & $0.98 \pm 0.17$ & $1.15 \pm 0.20$ & $0.30 \pm 0.13$ & $0.33 \pm 0.02$ & $2.6 \pm 0.4$ & $2.97 \pm 0.42$ \\
\hline Sn & 118 & $6.1 \pm 1.0$ & $6.80 \pm 0.85$ & $3.0 \pm 0.4$ & $3.52 \pm 0.41$ & $2.5 \pm 0.4$ & $3.01 \pm 0.33$ & $5.7 \pm 1.3$ & $6.39 \pm 1.1$ \\
\hline $\mathrm{La}$ & 139 & $34 \pm 3$ & $36.25 \pm 3.1$ & $164 \pm 16$ & $175.25 \pm 15$ & $21 \pm 2$ & $22.31 \pm 2.3$ & $53 \pm 6$ & $50.88 \pm 5.2$ \\
\hline $\mathrm{Ce}$ & 140 & $70 \pm 5$ & $73.23 \pm 5.2$ & $402 \pm 25$ & $427.22 \pm 28$ & $39 \pm 6$ & $40.26 \pm 5.5$ & $136 \pm 16$ & $125.20 \pm 10$ \\
\hline $\operatorname{Pr}$ & 141 & $7.5 \pm 0.5$ & $8.22 \pm 0.8$ & $57 \pm 6$ & $58.80 \pm 6.5$ & $4.8 \pm 0.4$ & $4.77 \pm 0.35$ & $8.4 \pm 1.9$ & $7.80 \pm 1.8$ \\
\hline $\mathrm{Nd}$ & 143 & $28 \pm 3$ & $28.31 \pm 2.8$ & $210 \pm 22$ & $197.35 \pm 20$ & $18.4 \pm 2.4$ & $16.20 \pm 3.1$ & $27 \pm 3$ & $25.15 \pm 4$ \\
\hline $\mathrm{Sm}$ & 147 & $5.2 \pm 0.4$ & $5.61 \pm 0.52$ & $18 \pm 3$ & $20.29 \pm 2.8$ & $3.3 \pm 0.3$ & $3.32 \pm 0.32$ & $4.4 \pm 0.5$ & $4.72 \pm 0.44$ \\
\hline $\mathrm{Eu}$ & 151 & $1.0 \pm 0.1$ & $1.22 \pm 0.11$ & $3.0 \pm 0.3$ & $3.27 \pm 0.33$ & $0.72 \pm 0.06$ & $0.80 \pm 0.05$ & $0.85 \pm 0.11$ & $0.96 \pm 0.12$ \\
\hline Gd & 158 & $4.6 \pm 0.3$ & $4.82 \pm 0.29$ & $7.8 \pm 0.6$ & $8.22 \pm 0.75$ & $2.9 \pm 0.4$ & $3.20 \pm 0.4$ & $4.7 \pm 0.6$ & $5.15 \pm 0.72$ \\
\hline $\mathrm{Tb}$ & 159 & $0.75 \pm 0.09$ & $0.85 \pm 0.08$ & $0.97 \pm 0.40$ & $1.50 \pm 0.8$ & $0.49 \pm 0.09$ & $0.46 \pm 0.06$ & $0.94 \pm 0.13$ & $1.02 \pm 0.12$ \\
\hline Dy & 164 & $4.6 \pm 0.3$ & $4.96 \pm 0.04$ & $4.4 \pm 0.3$ & $4.62 \pm 0.4$ & $2.6 \pm 0.2$ & $2.68 \pm 0.25$ & $6.6 \pm 0.7$ & $7.19 \pm 0.75$ \\
\hline Ho & 165 & $0.87 \pm 0.08$ & $0.95 \pm .07$ & $0.93 \pm 0.15$ & $0.76 \pm 0.18$ & $0.53 \pm 0.07$ & $0.53 \pm 0.06$ & $1.46 \pm 0.14$ & $1.55 \pm 0.16$ \\
\hline $\mathrm{Er}$ & 167 & $2.6 \pm 0.2$ & $2.85 \pm 0.19$ & $2.1 \pm 0.4$ & $2.15 \pm 0.35$ & $1.5 \pm 0.3$ & $1.62 \pm 0.41$ & $4.5 \pm 0.8$ & $4.91 \pm 0.9$ \\
\hline $\mathrm{Tm}$ & 169 & $0.42 \pm 0.07$ & $0.48 \pm 0.04$ & $0.42 \pm 0.13$ & $0.33 \pm 0.09$ & $0.28 \pm 0.06$ & $0.27 \pm 0.08$ & $0.70 \pm 0.12$ & $0.84 \pm 0.15$ \\
\hline $\mathrm{Yb}$ & 172 & $2.7 \pm 0.4$ & $3.05 \pm 0.5$ & $2.0 \pm 0.3$ & $2.13 \pm 0.25$ & $1.7 \pm 0.3$ & $1.77 \pm 0.4$ & $4.8 \pm 0.8$ & $5.52 \pm 0.9$ \\
\hline $\mathrm{Lu}$ & 175 & $0.41 \pm 0.06$ & $0.45 \pm 0.04$ & $0.32 \pm 0.06$ & $0.34 \pm 0.06$ & $0.29 \pm 0.03$ & $0.31 \pm 0.02$ & $0.75 \pm 0.09$ & $0.89 \pm 0.10$ \\
\hline $\mathrm{Hf}$ & 178 & $6.8 \pm 0.9$ & $7.34 \pm 0.8$ & $5.8 \pm 0.9$ & $5.64 \pm 1.1$ & $6.8 \pm 0.9$ & $7.75 \pm 1.0$ & $14 \pm 2$ & $14.76 \pm 2.1$ \\
\hline $\mathrm{Ta}$ & 181 & $1.4 \pm 0.2$ & $1.45 \pm 0.15$ & $0.78 \pm 0.18$ & $0.75 \pm 0.15$ & $0.76 \pm 0.20$ & $0.73 \pm 0.22$ & $3.1 \pm 0.3$ & $2.83 \pm 0.28$ \\
\hline W & 182 & $3.1 \pm 0.4$ & $3.46 \pm 0.033$ & $1.08 \pm 0.33$ & $1.28 \pm 0.23$ & $0.95 \pm 0.29$ & $0.82 \pm 0.30$ & $6.2 \pm 0.7$ & $7.45 \pm 0.7$ \\
\hline $\mathrm{U}$ & 238 & $3.3 \pm 0.6$ & $3.18 \pm 0.056$ & $1.4 \pm 0.4$ & $1.39 \pm 0.29$ & $1.3 \pm 0.4$ & $1.17 \pm 0.25$ & $6.7 \pm 1.2$ & $7.31 \pm 1.1$ \\
\hline
\end{tabular}

${ }^{\text {a }}$ Certificate of Certified values of Stream Sediment and Soil Reference Materials, 1998 Revision by Quality and Technical Supervision, P.R. China. 
TABLE- IV (continued)

Data of ICP-MS Analysis for Chinese Soil Reference Samples $(\mu \mathrm{g} / \mathrm{g})$

\begin{tabular}{|c|c|c|c|c|c|c|c|c|c|}
\hline \multirow{2}{*}{\multicolumn{2}{|c|}{ Element/Mass }} & \multicolumn{2}{|c|}{ GSS-5 } & \multicolumn{2}{|c|}{ GSS-6 } & \multicolumn{2}{|c|}{ GSS-7 } & \multicolumn{2}{|c|}{ GSS-8 } \\
\hline & & Certified $^{\mathrm{a}}$ & Obtained & Certified $^{\mathrm{a}}$ & Obtained & Certified $^{\mathrm{a}}$ & Obtained & Certified $^{\mathrm{a}}$ & Obtained \\
\hline $\mathrm{Be}$ & 9 & $2.0 \pm 0.5$ & $1.66 \pm 0.44$ & $4.4 \pm 1.0$ & $4.45 \pm 0.85$ & $2.8 \pm 0.9$ & $2.99 \pm 1.0$ & $1.9 \pm 0.3$ & $1.87 \pm 0.4$ \\
\hline $\mathrm{Ge}$ & 74 & $2.6 \pm 0.4$ & $2.36 \pm 0.5$ & $3.2 \pm 0.4$ & $3.06 \pm 0.36$ & $1.6 \pm 0.3$ & $1.69 \pm 0.21$ & $1.27 \pm 0.22$ & $1.29 \pm 0.20$ \\
\hline Mo & 98 & $4.6 \pm 0.5$ & $4.46 \pm 0.6$ & $18 \pm 3$ & $19.10 \pm 2.8$ & $2.9 \pm 0.4$ & $3.42 \pm 0.3$ & $1.16 \pm 0.15$ & $1.81 \pm 0.19$ \\
\hline Sn & 118 & $18 \pm 4$ & $20.57 \pm 3.2$ & $72 \pm 10$ & $80.57 \pm 8.5$ & $3.6 \pm 1.6$ & $4.75 \pm 1.5$ & $2.8 \pm 0.7$ & $3.15 \pm 0.82$ \\
\hline $\mathrm{La}$ & 139 & $36 \pm 6$ & $32.12 \pm 5.6$ & $30 \pm 3$ & $27.93 \pm 2.5$ & $46 \pm 7$ & $51.50 \pm 6.5$ & $36 \pm 4$ & $41.07 \pm 4.2$ \\
\hline $\mathrm{Ce}$ & 140 & $91 \pm 15$ & $78.15 \pm 16$ & $66 \pm 8$ & $58.99 \pm 6.1$ & $98 \pm 16$ & $110.12 \pm 12$ & $66 \pm 10$ & $74.06 \pm 8.5$ \\
\hline $\operatorname{Pr}$ & 141 & $7.0 \pm 1.3$ & $5.74 \pm 1.6$ & $5.8 \pm 0.6$ & $5.58 \pm 0.5$ & $11 \pm 1$ & $12.12 \pm 1.2$ & $8.3 \pm 0.9$ & $8.91 \pm 0.85$ \\
\hline $\mathrm{Nd}$ & 143 & $24 \pm 2$ & $23.15 \pm 2.5$ & $21 \pm 3$ & $17.63 \pm 2.5$ & $45 \pm 3$ & $42.97 \pm 3.4$ & $32 \pm 3$ & $28.49 \pm 2.6$ \\
\hline $\mathrm{Sm}$ & 147 & $4.0 \pm 0.6$ & $3.84 \pm 0.5$ & $3.8 \pm 0.6$ & $3.94 \pm 0.44$ & $10.3 \pm 0.6$ & $10.04 \pm 0.8$ & $5.9 \pm 0.6$ & $6.28 \pm 0.65$ \\
\hline Eu & 151 & $0.82 \pm 0.06$ & $0.73 \pm 0.07$ & $0.66 \pm 0.06$ & $0.77 \pm 0.05$ & $3.4 \pm 0.3$ & $3.08 \pm 0.4$ & $1.2 \pm 0.1$ & $1.32 \pm 0.12$ \\
\hline Gd & 158 & $3.5 \pm 0.3$ & $3.78 \pm 0.4$ & $3.4 \pm 0.3$ & $3.65 \pm 0.41$ & $9.6 \pm 1.0$ & $10.76 \pm 1.33$ & $5.4 \pm 0.5$ & $5.75 \pm 0.52$ \\
\hline $\mathrm{Tb}$ & 159 & $0.7 \pm 0.2$ & $0.54 \pm 0.15$ & $0.61 \pm 0.12$ & $0.57 \pm 0.11$ & $1.3 \pm 0.3$ & $1.47 \pm 0.25$ & $0.89 \pm 0.12$ & $0.89 \pm 0.14$ \\
\hline Dy & 164 & $3.7 \pm 0.6$ & $3.36 \pm 0.4$ & $3.3 \pm 0.3$ & $3.42 \pm 0.31$ & $6.6 \pm 0.8$ & $7.32 \pm 0.77$ & $4.8 \pm 0.5$ & $5.15 \pm 0.48$ \\
\hline Ho & 165 & $0.8 \pm 0.2$ & $0.69 \pm 0.18$ & $0.69 \pm 0.06$ & $0.68 \pm 0.06$ & $1.1 \pm 0.2$ & $1.21 \pm 0.18$ & $0.97 \pm 0.08$ & $0.99 \pm 0.09$ \\
\hline $\mathrm{Er}$ & 167 & $2.4 \pm 0.3$ & $2.22 \pm 0.24$ & $2.2 \pm 0.3$ & $2.19 \pm 0.24$ & $2.7 \pm 0.6$ & $3.10 \pm 0.56$ & $2.8 \pm 0.2$ & $2.93 \pm 0.26$ \\
\hline $\mathrm{Tm}$ & 169 & $0.41 \pm 0.05$ & $0.37 \pm 0.04$ & $0.40 \pm 0.07$ & $0.38 \pm 0.06$ & $0.42 \pm 0.06$ & $0.45 \pm 0.05$ & $0.46 \pm 0.08$ & $0.47 \pm 0.08$ \\
\hline $\mathrm{Yb}$ & 172 & $2.8 \pm 0.5$ & $2.41 \pm 0.42$ & $2.7 \pm 0.5$ & $2.73 \pm 0.45$ & $2.4 \pm 0.6$ & $2.73 \pm 0.52$ & $2.8 \pm 0.3$ & $3.01 \pm 0.3$ \\
\hline $\mathrm{Lu}$ & 175 & $0.42 \pm 0.07$ & $0.4 \pm 0.07$ & $0.42 \pm 0.06$ & $0.46 \pm 0.04$ & $0.35 \pm 0.08$ & $0.42 \pm 0.06$ & $0.38 \pm 0.07$ & $0.48 \pm 0.06$ \\
\hline Hf & 178 & $8.1 \pm 1.7$ & $7.75 \pm 1.3$ & $7.5 \pm 0.8$ & $7.73 \pm 0.72$ & $7.7 \pm 0.4$ & $7.85 \pm 0.6$ & $7.0 \pm 0.8$ & $7.70 \pm 0.08$ \\
\hline $\mathrm{Ta}$ & 181 & $1.8 \pm 0.3$ & $1.64 \pm 0.22$ & $5.3 \pm 0.6$ & $5.97 \pm 0.51$ & $3.9 \pm 0.6$ & $4.31 \pm 0.52$ & $1.05 \pm 0.26$ & $1.13 \pm 0.24$ \\
\hline W & 182 & $34 \pm 4$ & $33.27 \pm 3.5$ & $90 \pm 10$ & $99.01 \pm 8.5$ & $1.2 \pm 0.4$ & $1.71 \pm 0.35$ & $1.7 \pm 0.5$ & $2.27 \pm 0.42$ \\
\hline $\mathrm{U}$ & 238 & $6.5 \pm 1.1$ & $5.23 \pm 1.0$ & $6.7 \pm 1.1$ & $6.03 \pm 1.3$ & $2.2 \pm 0.5$ & $2.19 \pm 0.45$ & $2.7 \pm 0.5$ & $2.39 \pm 0.25$ \\
\hline
\end{tabular}

${ }^{a}$ Certificate of Certified Values of tream Sediment and Soil Reference Materials 1998 Revision by quality and Technical Supervisiion, P.R. China.

TABLE- IV (continued)

Data of ICP-MS Analysis for Stream Sediment Samples $(\mu \mathrm{g} / \mathrm{g})$

\begin{tabular}{|c|c|c|c|c|c|c|c|c|c|}
\hline \multirow{2}{*}{\multicolumn{2}{|c|}{ Element/Mass }} & \multicolumn{2}{|c|}{ STSD-1 } & \multicolumn{2}{|c|}{ STSD-2 } & \multicolumn{2}{|c|}{ STSD-3 } & \multicolumn{2}{|c|}{ STSD-4 } \\
\hline & & Certified & Obtained & Certified & Obtained & Certified & Obtained & Certified & Obtained \\
\hline $\mathrm{Be}$ & 9 & 1.60 & $1.51 \pm 0.35$ & 5.20 & $4.82 \pm 0.8$ & 2.60 & $2.10 \pm 0.3$ & 1.70 & $1.57 \pm 0.03$ \\
\hline $\mathrm{Ge}$ & 74 & $<1$ & $1.05 \pm 0.20$ & $<$ & $1.27 \pm 0.25$ & $<$ & $1.24 \pm 0.22$ & $<$ & $1.07 \pm 0.08$ \\
\hline Mo & 98 & 2.00 & $1.95 \pm 0.4$ & 13.00 & $12.95 \pm 1.3$ & {$[6]$} & $6.46 \pm 0.5$ & 2.00 & $1.55 \pm 0.21$ \\
\hline Sn & 118 & 4.00 & $3.65 \pm 0.8$ & 5.00 & $4.59 \pm 0.74$ & 4.00 & $3.46 \pm 0.54$ & 2.00 & $2.35 \pm 0.45$ \\
\hline $\mathrm{La}$ & 139 & 30.00 & $32.20 \pm 3.4$ & 59.00 & $62.25 \pm 5.8$ & 39.00 & $41.52 \pm 3.2$ & 24.00 & $25.56 \pm 1.8$ \\
\hline $\mathrm{Ce}$ & 140 & 51.00 & $53.65 \pm 6.2$ & 93.00 & $96.42 \pm 8.5$ & 63.00 & $67.95 \pm 5.4$ & 44.00 & $46.27 \pm 2.8$ \\
\hline $\operatorname{Pr}$ & 141 & $7.4 \mathrm{a}$ & $8.93 \pm 0.81$ & 11.90 & $13.56 \pm 1.4$ & $8.9 \mathrm{a}$ & $10.19 \pm 1.2$ & $5.4 \mathrm{a}$ & $6.53 \pm 0.52$ \\
\hline $\mathrm{Nd}$ & 143 & 28.00 & $28.82 \pm 2.7$ & 43.00 & $43.09 \pm 3.1$ & 33.00 & $31.54 \pm 3.2$ & 21.00 & $19.64 \pm 1.8$ \\
\hline $\mathrm{Sm}$ & 147 & 6.00 & $6.45 \pm 0.6$ & 8.00 & $9.37 \pm 1.0$ & 7.00 & $7.27 \pm 0.8$ & 5.00 & $4.75 \pm 0.25$ \\
\hline $\mathrm{Eu}$ & 151 & 1.60 & $1.45 \pm 0.12$ & 2.00 & $1.91 \pm 0.25$ & 1.30 & $1.62 \pm 0.20$ & 1.20 & $1.18 \pm 0.04$ \\
\hline Gd & 158 & $6.5 \mathrm{a}$ & $6.42 \pm 0.52$ & $7.3 \mathrm{a}$ & $8.35 \pm 0.85$ & $6.5 \mathrm{a}$ & $6.62 \pm 0.52$ & $4.2 \mathrm{a}$ & $4.43 \pm 0.04$ \\
\hline $\mathrm{Tb}$ & 159 & 1.20 & $1.08 \pm 0.18$ & 1.30 & $1.26 \pm 0.10$ & 1.10 & $1.06 \pm 0.02$ & 0.80 & $0.74 \pm 0.06$ \\
\hline Dy & 164 & 5.60 & $5.85 \pm 0.35$ & 6.50 & $6.92 \pm 0.51$ & 5.40 & $6.04 \pm 0.56$ & 3.80 & $4.33 \pm 0.05$ \\
\hline Ho & 165 & $1.2 \mathrm{a}$ & $1.32 \pm 0.23$ & $1.2 \mathrm{a}$ & $1.31 \pm 0.02$ & $1.2 \mathrm{a}$ & $1.19 \pm 0.02$ & $0.75 \mathrm{a}$ & $0.86 \pm 0.06$ \\
\hline $\mathrm{Er}$ & 167 & $3.6 \mathrm{a}$ & $3.93 \pm 0.42$ & $3.2 \mathrm{a}$ & $3.78 \pm 0.19$ & $3.2 \mathrm{a}$ & $3.55 \pm 0.65$ & $2.1 \mathrm{a}$ & $2.62 \pm 0.04$ \\
\hline $\mathrm{Tm}$ & 169 & $0.5 \mathrm{a}$ & $0.63 \pm 0.10$ & $0.47 \mathrm{a}$ & $0.61 \pm 0.02$ & $0.47 \mathrm{a}$ & $0.57 \pm 0.06$ & $0.33 \mathrm{a}$ & $0.42 \pm 0.02$ \\
\hline $\mathrm{Yb}$ & 172 & 4.00 & $3.95 \pm 0.75$ & 3.70 & $3.78 \pm 0.05$ & 3.40 & $3.59 \pm 0.25$ & 2.60 & $2.64 \pm 0.24$ \\
\hline $\mathrm{Lu}$ & 175 & 0.80 & $0.65 \pm 0.17$ & 0.70 & $0.60 \pm 0.05$ & 0.80 & $0.60 \pm 0.15$ & 0.50 & $0.44 \pm 0.04$ \\
\hline $\mathrm{Hf}$ & 178 & 6.10 & $6.33 \pm 0.55$ & 5.00 & $6.29 \pm 1.8$ & 5.10 & $6.66 \pm 0.55$ & 5.50 & $6.14 \pm 0.55$ \\
\hline $\mathrm{Ta}$ & 181 & 0.40 & $0.42 \pm 0.03$ & 1.60 & $1.67 \pm 0.06$ & 0.90 & $0.91 \pm 0.08$ & 0.60 & $0.56 \pm 0.05$ \\
\hline W & 182 & $<4$ & $0.57 \pm 0.07$ & 7.00 & $6.37 \pm 0.05$ & $<4$ & $1.58 \pm 0.12$ & $<4$ & $0.23 \pm 0.03$ \\
\hline $\mathrm{U}$ & 238 & 8.00 & $7.57 \pm 0.82$ & 18.60 & $16.55 \pm 1.50$ & 10.50 & $9.85 \pm 1.0$ & 3.00 & $2.11 \pm 0.82$ \\
\hline
\end{tabular}

${ }^{a}$ Geostandard Newsletter, Special issue of Geostandard Newsletter, Vol.XVIII, July, 1994 a Data from J.G. Sebgupta et al., Talanta 42, 1947 (1995). 


\section{Atomic Mpectroscopy \\ $\bigcup$ Vol. 33(5), Sept./Oct. 2012}

TABLE- IV (continued)

Data of ICP-MS Analysis for Japanese Stream Sedimen Samples ( $\mu \mathrm{g} / \mathrm{g})$

\begin{tabular}{|c|c|c|c|c|c|c|c|}
\hline \multirow{2}{*}{\multicolumn{2}{|c|}{ Element/Mass }} & \multicolumn{2}{|c|}{ JSD-1 } & \multicolumn{2}{|c|}{ JSD-2 } & \multicolumn{2}{|c|}{ JSD-3 } \\
\hline & & \multirow{2}{*}{$\frac{\text { Certified }^{\mathrm{a}}}{1.30}$} & \multirow{2}{*}{$\begin{array}{r}\text { Obtained } \\
1.13 \pm 0.3\end{array}$} & \multirow{2}{*}{$\begin{array}{c}\text { Certified }^{\mathrm{a}} \\
0.80\end{array}$} & \multirow{2}{*}{$\begin{array}{r}\text { Obtained } \\
0.90 \pm 0.4\end{array}$} & \multirow{2}{*}{$\frac{\text { Certified }^{\mathrm{a}}}{10}$} & \multirow{2}{*}{$\begin{array}{c}\text { Obtained } \\
7.63 \pm 1.2\end{array}$} \\
\hline $\mathrm{Be}$ & 9 & & & & & & \\
\hline $\mathrm{Ge}$ & 74 & $<$ & $0.87 \pm 0.28$ & $<$ & $1.12 \pm 0.32$ & $<$ & $2.98 \pm 0.75$ \\
\hline Mo & 98 & $<$ & $0.38 \pm 0.12$ & $<$ & $15.60 \pm 2.1$ & $<$ & $1.38 \pm 0.3$ \\
\hline Sn & 118 & $<$ & $2.31 \pm 0.45$ & $<$ & $38.27 \pm 4.2$ & $<$ & $183.75 \pm 23$ \\
\hline $\mathrm{La}$ & 139 & 18.60 & $22.18 \pm 4.2$ & 12.30 & $15.22 \pm 3.5$ & 20.1 & $20.38 \pm 3.8$ \\
\hline $\mathrm{Ce}$ & 140 & 35.40 & $39.90 \pm 5.0$ & 20.70 & $27.92 \pm 5.2$ & 41.4 & $38.65 \pm 4.7$ \\
\hline $\operatorname{Pr}$ & 141 & 4.00 & $5.16 \pm 0.5$ & 2.30 & $3.69 \pm 0.45$ & 3.8 & $4.39 \pm 0.41$ \\
\hline $\mathrm{Nd}$ & 143 & 17.80 & $16.21 \pm 2.1$ & 13.20 & $11.71 \pm 1.8$ & 16.5 & $13.38 \pm 2.0$ \\
\hline Sm & 147 & 3.87 & $3.76 \pm 0.3$ & 3.00 & $2.75 \pm 0.4$ & 3.71 & $3.12 \pm 0.28$ \\
\hline $\mathrm{Eu}$ & 151 & 0.92 & $0.84 \pm 0.22$ & 0.80 & $0.77 \pm 0.21$ & 0.7 & $0.66 \pm 0.20$ \\
\hline Gd & 158 & 2.60 & $3.31 \pm 0.5$ & 2.80 & $2.93 \pm 0.45$ & 2.8 & $2.86 \pm 0.40$ \\
\hline $\mathrm{Tb}$ & 159 & 0.40 & $0.51 \pm 0.08$ & 0.40 & $0.53 \pm 0.07$ & 0.3 & $0.43 \pm 0.06$ \\
\hline Dy & 164 & 2.10 & $2.92 \pm 0.44$ & 2.80 & $3.32 \pm 0.45$ & 2.2 & $2.49 \pm 0.40$ \\
\hline Ho & 165 & 0.30 & $0.53 \pm 0.07$ & 0.60 & $0.67 \pm 0.08$ & 0.5 & $0.48 \pm 0.06$ \\
\hline $\mathrm{Er}$ & 167 & 0.60 & $1.53 \pm 0.25$ & 1.30 & $2.02 \pm 0.32$ & 0.9 & $1.42 \pm 0.20$ \\
\hline $\mathrm{Tm}$ & 169 & $<$ & $0.24 \pm 0.06$ & 0.20 & $0.34 \pm 0.05$ & 0.2 & $0.25 \pm 0.05$ \\
\hline $\mathrm{Yb}$ & 172 & 1.39 & $1.50 \pm 0.4$ & 1.59 & $2.16 \pm 0.55$ & 1.21 & $1.55 \pm 0.40$ \\
\hline $\mathrm{Lu}$ & 175 & 0.20 & $0.24 \pm 0.07$ & 0.20 & $0.35 \pm 0.06$ & 0.2 & $0.26 \pm 0.06$ \\
\hline $\mathrm{Hf}$ & 178 & 3.40 & $4.23 \pm 1.1$ & 2.80 & $3.66 \pm 0.9$ & 3.2 & $3.84 \pm 1.00$ \\
\hline $\mathrm{Ta}$ & 181 & $<$ & $0.91 \pm 0.25$ & $<$ & $0.40 \pm 0.18$ & $<$ & $0.57 \pm 0.20$ \\
\hline W & 182 & $<$ & $0.24 \pm 0.08$ & $<$ & $3.82 \pm 0.07$ & $<$ & $177.02 \pm 15$ \\
\hline $\mathrm{U}$ & 238 & $<$ & $1.08 \pm 0.15$ & $<$ & $0.94 \pm 0.19$ & $<$ & $1.16 \pm 0.20$ \\
\hline
\end{tabular}

${ }^{a}$ Data from K. Yamamoto et al., Geochemical Journal, Vol. 39, pp 289-297, 2005.

TABLE IV (continued)

Data of ICP-MS Analysis for SRM ( $\mu \mathrm{g} / \mathrm{g})$

\begin{tabular}{|c|c|c|c|c|c|c|c|c|c|}
\hline \multirow{2}{*}{\multicolumn{2}{|c|}{ Element/Mass }} & \multicolumn{2}{|c|}{ SARM 42} & \multicolumn{2}{|c|}{ SARM 46} & \multicolumn{2}{|c|}{ SARM 51} & \multicolumn{2}{|c|}{ SARM 52} \\
\hline & & Certified $^{\mathrm{a}}$ & Obtained & Certified $^{\mathrm{a}}$ & Obtained & Certified $^{\mathrm{a}}$ & Obtained & Certified $^{\mathrm{a}}$ & Obtained \\
\hline $\mathrm{Be}$ & 9 & & $0.59 \pm 0.08$ & & $1.04 \pm 0.2$ & & $1.26 \pm 0.2$ & & $1.85 \pm 0.2$ \\
\hline $\mathrm{Ge}$ & 74 & & $0.97 \pm 0.36$ & & $1.50 \pm 0.45$ & & $1.58 \pm 0.1$ & & $1.66 \pm 0.18$ \\
\hline Mo & 98 & & $0.44 \pm 0.2$ & & $0.99 \pm 0.4$ & & $1.35 \pm 0.18$ & & $2.75 \pm 0.3$ \\
\hline Sn & 118 & & $8.24 \pm 1.6$ & & $17.64 \pm 2.6$ & & $45.05 \pm 5.0$ & & $2.65 \pm 0.26$ \\
\hline $\mathrm{La}$ & 139 & 13.57 & $30.59 \pm 3.9$ & 19 & $17.75 \pm 1.6$ & 20.80 & $26.92 \pm 2.8$ & 15.80 & $18.75 \pm 2.2$ \\
\hline $\mathrm{Ce}$ & 140 & 28.40 & $53.75 \pm 5.2$ & 66 & $46.55 \pm 4.2$ & 53.00 & $54.19 \pm 4.6$ & 144.00 & $87.90 \pm 7.8$ \\
\hline $\operatorname{Pr}$ & 141 & 3.00 & $6.46 \pm 1.2$ & n.a & $3.95 \pm 0.8$ & n.a & $6.00 \pm 1.3$ & n.a & $4.06 \pm 0.4$ \\
\hline $\mathrm{Nd}$ & 143 & 10.70 & $19.79 \pm 2.1$ & 32.00 & $12.08 \pm 1.6$ & 22.00 & $18.73 \pm 2.0$ & 14.00 & $13.98 \pm 2.3$ \\
\hline $\mathrm{Sm}$ & 147 & 2.20 & $4.31 \pm 0.8$ & 3.4 & $2.94 \pm 0.6$ & 3.97 & $4.37 \pm 0.7$ & 3.17 & $2.93 \pm 0.22$ \\
\hline $\mathrm{Eu}$ & 151 & 0.53 & $0.67 \pm 0.7$ & 0.74 & $0.66 \pm 0.7$ & 0.90 & $0.91 \pm 0.21$ & 0.72 & $0.66 \pm 0.10$ \\
\hline Gd & 158 & 1.80 & $3.12 \pm 0.8$ & 3.00 & $3.55 \pm 0.8$ & 3.20 & $4.49 \pm 0.8$ & 2.80 & $3.99 \pm 0.7$ \\
\hline $\mathrm{Tb}$ & 159 & 0.31 & $0.46 \pm 0.3$ & 0.50 & $0.51 \pm 0.15$ & 0.55 & $0.68 \pm 0.15$ & 0.50 & $0.50 \pm 0.10$ \\
\hline Dy & 164 & 2.00 & $2.76 \pm 0.30$ & 2.80 & $2.94 \pm 0.28$ & 3.40 & $4.03 \pm 0.6$ & 3.20 & $3.10 \pm 0.28$ \\
\hline Ho & 165 & 0.44 & $0.58 \pm 0.04$ & 0.55 & $0.55 \pm 0.05$ & 0.73 & $0.76 \pm 0.2$ & 0.73 & $0.61 \pm 0.16$ \\
\hline $\mathrm{Er}$ & 167 & 1.20 & $1.81 \pm 0.15$ & 1.40 & $1.56 \pm 0.18$ & 2.00 & $2.36 \pm 0.25$ & 2.10 & $1.89 \pm 0.19$ \\
\hline $\mathrm{Tm}$ & 169 & 0.19 & $0.29 \pm 0.05$ & 0.18 & $0.24 \pm 0.02$ & 0.29 & $0.37 \pm 0.05$ & 0.32 & $0.32 \pm 0.04$ \\
\hline $\mathrm{Yb}$ & 172 & 1.25 & $1.86 \pm 0.4$ & 1.11 & $1.46 \pm 0.21$ & 1.80 & $2.37 \pm 0.3$ & 2.14 & $2.08 \pm 0.3$ \\
\hline $\mathrm{Lu}$ & 175 & 0.19 & $0.30 \pm 0.04$ & 0.17 & $0.23 \pm 0.01$ & 0.27 & $0.37 \pm 0.04$ & 0.32 & $0.33 \pm 0.02$ \\
\hline Hf & 178 & 5.27 & $5.58 \pm 1.8$ & 2.54 & $3.64 \pm 0.31$ & 3.48 & $4.73 \pm 0.41$ & 7.70 & $7.35 \pm 1.2$ \\
\hline $\mathrm{Ta}$ & 181 & 0.40 & $0.45 \pm 0.02$ & 0.30 & $0.42 \pm 0.02$ & 0.68 & $0.73 \pm 0.2$ & 0.82 & $0.75 \pm 0.07$ \\
\hline W & 182 & 0.61 & $0.44 \pm 0.02$ & $<20$ & $3.12 \pm 0.2$ & 49.00 & $59.61 \pm 5.2$ & $<5$ & $1.53 \pm 0.03$ \\
\hline $\mathrm{U}$ & 238 & 1.17 & $0.96 \pm 0.08$ & 1.40 & $1.11 \pm 0.02$ & 1.93 & $1.97 \pm 0.12$ & 2.90 & $2.15 \pm 0.3$ \\
\hline
\end{tabular}

${ }^{a}$ Data from Korotev, Geostandards Newsletter 20 (217-245), (1996). 
TABLE IV (continued) Data of ICP-MS Analysis for SRM ( $\mu \mathrm{g} / \mathrm{g})$

\begin{tabular}{|c|c|c|c|c|c|}
\hline \multirow{2}{*}{\multicolumn{2}{|c|}{ Element/Mass }} & \multicolumn{2}{|c|}{ So- 2} & \multicolumn{2}{|c|}{ So-3 } \\
\hline & & \multirow{2}{*}{$\frac{\text { Certified }^{\mathrm{a}}}{2.00}$} & \multirow{2}{*}{$\begin{array}{l}\text { Obtained } \\
1.96 \pm 0.18\end{array}$} & \multirow{2}{*}{$\begin{array}{c}\text { Certified }^{\mathrm{a}} \\
0.81\end{array}$} & \multirow{2}{*}{$\begin{array}{l}\text { Obtained } \\
0.79 \pm 0.11\end{array}$} \\
\hline $\mathrm{Be}$ & 9 & & & & \\
\hline Ge & 74 & 1.50 & $1.20 \pm 0.15$ & 3.40 & $0.50 \pm 0.18$ \\
\hline Mo & 98 & 2.00 & $1.73 \pm 0.2$ & 2.00 & $0.78 \pm 0.19$ \\
\hline Sn & 118 & 2.60 & $2.08 \pm 0.25$ & 0.97 & $1.46 \pm 0.25$ \\
\hline $\mathrm{La}$ & 139 & 46.50 & $65.44 \pm 5.8$ & 16.90 & $21.45 \pm 4.7$ \\
\hline $\mathrm{Ce}$ & 140 & 112.00 & $125.53 \pm 10.2$ & 34.00 & $38.92 \pm 4.6$ \\
\hline $\operatorname{Pr}$ & 141 & 14.30 & $15.93 \pm 2.3$ & 4.60 & $4.92 \pm 0.5$ \\
\hline $\mathrm{Nd}$ & 143 & 57.00 & $55.82 \pm 5.8$ & 17.20 & $17.05 \pm 2.7$ \\
\hline $\mathrm{Sm}$ & 152 & 11.80 & $11.33 \pm 1.9$ & 3.47 & $3.39 \pm 0.4$ \\
\hline $\mathrm{Eu}$ & 151 & 3.15 & $2.50 \pm 0.24$ & 0.74 & $0.74 \pm 0.21$ \\
\hline Gd & 158 & 11.10 & $10.22 \pm 1.8$ & 3.12 & $3.17 \pm 0.6$ \\
\hline $\mathrm{Tb}$ & 159 & 1.62 & $1.55 \pm 0.14$ & 0.50 & $0.50 \pm 0.11$ \\
\hline Dy & 164 & 8.80 & $8.40 \pm 1.6$ & 2.80 & $2.86 \pm 0.28$ \\
\hline Ho & 165 & 1.70 & $1.45 \pm 0.33$ & 0.60 & $0.55 \pm 0.19$ \\
\hline $\mathrm{Er}$ & 167 & 4.20 & $3.92 \pm 0.4$ & 1.85 & $1.62 \pm 0.2$ \\
\hline $\mathrm{Tm}$ & 169 & 0.54 & $0.60 \pm 0.05$ & 0.30 & $0.26 \pm 0.04$ \\
\hline $\mathrm{Yb}$ & 172 & 3.50 & $3.66 \pm 0.4$ & 1.67 & $1.66 \pm 0.35$ \\
\hline $\mathrm{Lu}$ & 175 & 0.46 & $0.56 \pm 0.06$ & 0.23 & $0.26 \pm 0.02$ \\
\hline Hf & 178 & 17.40 & $14.36 \pm 1.4$ & 4.29 & $4.57 \pm 0.04$ \\
\hline $\mathrm{Ta}$ & 181 & 1.15 & $0.17 \pm 0.04$ & 0.43 & $0.19 \pm 0.02$ \\
\hline W & 182 & & $0.19 \pm 0.05$ & 0.40 & $0.31 \pm 0.02$ \\
\hline $\mathrm{U}$ & 238 & 0.98 & $0.71 \pm 0.08$ & 1.11 & $0.82 \pm 0.04$ \\
\hline
\end{tabular}

${ }^{a}$ Geostandards Newsletter, Special Issue of Geostandards Newsletter, Vol. XVIII (July, 1994).

\section{REFERENCES}

1. S.K. Bhadury, D. Banerjee, J.B. Ghosh, C. Saha., N. K. Roy and D.K Das. Indian Minerals 59, 115 (2005).

2. G.A. Jenner, H.P. Longerich, S.J. Jackson and B.J. Fryer, Chem. Geol. 83, 133 (1990)

3. G.E.M. Hall and J.C. Pelchat, Geostds. Newsl. 14, 197 (1990).

4. C.D. Garbe-Schonberg, Geostds. Newsl. 17, 81 (1993).

5. M. Totland, I. Jarvis., and K.E. Jarvis. Chem. Geol. 95, 35 (1992).

6. K.E. Jarvis, Chem. Geol. 83, 89 (1990).

7. K. Yamamoto, F. Yamashita and M. Adachi., Geochem. J. 39, 289 (2005).

8. Q. Liang and D.C. Gregoire, Geostds. Newsl. 24, 51 (1999).

9. S. Revillion and D. Hurean Mazumdier, Geostds. and Geoanal. Res. 33, 397 (2009).

10. P.J. Lamothe, T.L. Fries and J.J. Consul, Anal. Chem. 58, 1881 (1986).

11. S. Kokot, G. King and H.R. Keller, Anal. Chim. Acta 259, 267 (1992).

12. C.Y. Zhou, M.K. Wong and L.L. Koh., Anal. Chim. Acta 314, 121 (1995).

13. J.G. Sen Gupta and N.B. Bertrand, Talanta 42, 1595 (1995).

14. J. Ivanova, R. Djingova., S.Korhammer and B. Markert, Talanta 54, 567 (2001).

15. A.K. Nandy, J.K. Manjhi and N.K. Roy, At. Spectrosc. 29, 115 (2008).

16. D. Taicheng, C.Hangting and $Z$. Xianjin, J. Anal. At. Spectrom. 17, 410 (2002).

17. G. Bayon, J.A. Barrat, J. Etoubleu, M. Benoit, C. Bellinger and S. Revillion, Geostds. and Geoanal. Res. 33, 59 (2009).

18. Certified Values of Stream Sediment and Soil Reference Materials, 1998 Revision by Quality and Technical Supervision, P.R. China.

19. K Govindaraju, Geostds. Newsl. 18 (Special Issue), 158 (1994).

20. R.L. Korotev, Geostds. Newsl. 20, 217 (1996) 